\title{
Enraizamento de estacas caulinares de acerola em função da composição do substrato
}

\section{Rooting of indian berry stem cuttings influenced by the substrate in dibble tubes}

\author{
Rosiane de Lourdes Silva de Lima'; Dalmo Lopes de Siqueira²; Olmar Baller \\ Weber $^{3}$; Dalva Maria Bueno ${ }^{3}$; Paulo Roberto Cecon ${ }^{2 *}$
}

Resumo

\begin{abstract}
A produção de mudas de espécies frutíferas é uma das mais importantes etapas do sistema produtivo. A formação de mudas por enraizamento de estacas é influenciada em grande parte pela composição do substrato, genótipo, recipiente e estádio fisiológica da planta matriz. Este trabalho objetivou avaliar os efeitos de diferentes substratos nas variáveis de crescimento de progênies de aceroleira obtidas por estaquia, em tubetes, sob condições de nebulização intermitente em casa de vegetação, durante 60 dias. Utilizou-se o delineamento de blocos casualizados em esquema fatorial de $4 \times 2$, (quatro fontes de matéria orgânica e dois genótipos). As fontes orgânicas de húmus, casca de arroz carbonizada, pó de casca de coco e bagana de carnaubeira foram misturadas ao Argissolo Vermelho-Amarelo distrófico (PVAd) (proporção 1:1) para o enraizamento dos genótipos P-91 e P-26. Foram mensurados a porcentagem de enraizamento, a massa das raízes secas $(\mathrm{g})$, o número de médio de folhas e a parte aérea seca $(\mathrm{g})$ das estacas. A mistura de húmus e solo propiciou condições adequadas para enraizamento de estacas e o crescimento das mudas, com reflexos no número de folhas e na massa seca da parte aérea. A progênie 26 apresentou potencial para a produção de mudas por estaquia.
\end{abstract}

Palavras-chave: Malpighia emarginata, estacas, enraizamento, substratos orgânicos

\begin{abstract}
The production of nursery is one of the most important steps in fruit crop systems. The rooting of semihardwood cuttings is largely influenced by the substrate composition, container, matrix genotype and physiological stage. The aim of this work was to evaluate the effect of different substratum composition on growth of berry plant genotypes propagated by stem cutting in dibble tubes condition under na intermittent nebulization system in green house, during 60 days. A block factorial design $(4 \times 2)$ comprising four organic sources e two berry genotypes was established. The organic sources of humus (vermicompost), carbonized rice hulls, ripe coir dust and leave dust from carnaúba (Copernicia cerifera) were mixed with na arenic Hapludult (1:1 proportions, v/v) to rooting and growth of P-91 and P-26 berry genotypes in tubules condition. Rooting percentage, dry mass of roots (g), number of leaves (NF) and dry mass of aerial part $(\mathrm{g})$ were measured. The soil and humus mixture was suitable for rooting of semihardwood cuttings and was reflected on the number of leaves and aerial dry mass accumulation.

The berry genotype P-26 presented potential for cutting process.
\end{abstract}

Key words: Malpighia emarginata, cutting, rooting, organic substrate

1 Eng ${ }^{\text {Ag }}$ Ms. Bolsista do Projeto Petrobrás, Embrapa Algodão. Rua: Osvaldo Cruz, 1143, Centenário, Campina Grande, PB, 58100 000; limarosiane@yahoo.com.br

2 Profs. Adjuntos, D.S., - Universidade Federal de Viçosa, Deptos. de Fitotecnia e Informática, respectivamente, 36570-000, Viçosa, MG.siqueira@ufv.br.

3 Eng Ag $^{\circ}$ D.Sc. Embrapa Agroindústria Tropical. Av. Dra. Sara Mesquita, 2270. Pici, Fortaleza, CE, $60511-110$. dalva@cnpat.embrapa.br,weber@cnpat.embrapa.br.

* Autor para correspondência. 


\section{Introdução}

A forma usual para a produção de mudas de aceroleira, geralmente consiste no uso de misturas empíricas de materiais, cujas características físicoquímicas, em sua maioria, são desconhecidas.

Para a obtenção de mudas de boa qualidade, tanto no aspecto nutricional como fitossanitário, é necessário dispor de materiais com características físicas e químicas conhecidas, além da facilidade de aquisição e custos para a obtenção (LIMA; CORREIA, 2001a).

Materiais tais como húmus (OLIVEIRA et al., 2000), casca de arroz carbonizada (MARCO; KERTEN; SILVA, 1998; SOUZA et al., 1995; OLIVEIRA et al., 2000), casca de coco seco (SOUZA, 2001), estercos de animais (ANDRADE NETO; MENDES; GUIMARÃES, 2000) dentre outros, tem sido largamente utilizados na formulação de substratos para o cultivo de diversas espécies frutíferas.

Entre os materiais orgânicos disponíveis em quantidade na região Nordeste, encontram-se o pó da casca do coco e a folha da carnaubeira, os quais podem ser utilizados em misturas com solo ou isolados como substratos para o cultivo de plantas. Porém, estes substratos podem ser inadequados e afetar seriamente a qualidade da muda, sendo necessários estudos de pesquisa que viabilizem a sua utilização para a produção de mudas.

Esta pesquisa teve como objetivo avaliar os efeitos da composição do substrato no enraizamento e formação de mudas de progênies de aceroleira, propagadas por estaquia, em condições de casa de vegetação.

\section{Materiais e Métodos}

O experimento foi conduzido em casa de vegetação da Embrapa Agroindústria Tropical, em Fortaleza, Ceará, no período de novembro/2001 a janeiro/2002. A casa tinha sistema de nebulização intermitente, controlado por timer, e os períodos de ativação nos dias ensolarados foram: 10 às $10: 15 \mathrm{~h}$, $11: 30$ às $11: 45,13: 00$ às $13: 15$ e 14:30 às $14: 45$. Nos dias nublados e chuvosos os períodos foram reduzidos para 3,2 ou 1 vez.

Foram utilizadas estacas caulinares semilenhosas retiradas de plantas matrizes (progênie 91 e 26), com 3,5 anos de idade, cultivadas no jardim clonal da área experimental de Pacajus, localizado no município de Pacajus, Ceará.

Após a coleta dos ramos, estes foram acondicionados em recipientes com água para evitar a desidratação. Retiraram-se duas estacas da parte mediana do caule, descartando o ápice e a base e removendo o excesso de folhas, deixando-se um par de folhas com $35 \%$ de área foliar. As estacas foram padronizadas em $12 \mathrm{~cm}$ de comprimento e foram cortadas transversalmente próximas a uma gema, na base, e horizontalmente na parte superior. Posteriormente, foram imersas em solução de Benomyl a 0,2\%, e em solução de ácido indolbutírico (AIB) (2000 ppm) por cinco segundos, conforme recomendação de Lima, Almeida e Almeida (1992).

Antes da elaboração dos substratos, as fontes orgânicas (húmus de minhoca, casca de arroz carbonizada, pó de casca de coco seco e bagana de carnaubeira) foram submetidas a análises químicas, tabela 1. Para a determinação do $\mathrm{pH}$, utilizou-se água na relação de 1:2, 5; do $\mathrm{Ca}, \mathrm{Mg}$, e $\mathrm{Al}$, extrator $\mathrm{KCl} 1$ mol/L; do P, Na, K, Fe, Zn, Mn e Cu, Mehlich 1 e $\mathrm{H}+\mathrm{Al}$, extrator acetato de cálcio $0,5 \mathrm{~mol} / \mathrm{L}-\mathrm{pH} 7,0$.

$\mathrm{Na}$ formulação dos substratos utilizaram-se amostras de solo coletado na faixa de $0,40 \mathrm{~cm}$ de profundidade classificado como Argissolo Vermelho Amarelo distrófico. Cada substrato foi formulado pela mistura de solo e uma das quatro fontes de matéria orgânica a seguir: húmus, casca de arroz carbonizada, pó de casca de coco seco e bagana de carnaubeira, na proporção de 1:1 v/v. Utilizou-se o Argissolo Vermelho-Amarelo distrófico coletado na camada de 0 a $40 \mathrm{~cm}$, em Pacajús, Ceará.

Os substratos formulados receberam adubação suplementar adicional conforme recomendação do 
laboratório de análises de solos da Universidade Federal de Viçosa. Utilizaram-se, segundo recomendações técnicas, $8,5 \mathrm{~g}$ de calcário/L de material $(3,4 \mathrm{t} / \mathrm{ha}), 0,166 \mathrm{~g} / \mathrm{L}$ de cloreto de potássio $(40 \mathrm{~kg} / \mathrm{ha}), 0,222 \mathrm{~g} / \mathrm{L}$ de uréia $(40 \mathrm{~kg} / \mathrm{ha})$ parcelada em quatro vezes, a partir de 30 dias pós-plantio, e $0,75 \mathrm{~g} /$ L de superfosfato simples $(60 \mathrm{~kg} / \mathrm{ha})$.

Foi usado o delineamento em blocos ao acaso, em esquema fatorial 4 x 2, com três repetições e 10 plantas por parcela. As fontes de matéria orgânica usadas foram: húmus, casca de arroz carbonizada, pó de casca de coco seco, bagana de carnaubeira. O segundo fator foi composto por dois genótipos de aceroleira (P-91 e P-26).

Após 60 dias, em casa de vegetação, foram avaliadas, em cada estaca, a massa da matéria seca do sistema radicular (g), percentagem de estacas enraizadas (\%), número de médio de folhas/planta (NF) e massa da matéria seca da parte aérea (g).

Os dados coletados foram submetidos à análise de variância, e as diferenças entre os fatores qualitativos foram analisadas pelo Teste de Tukey, ao nível de $5 \%$ de probabilidade.

\section{Resultados e Discussão}

Observando-se a FIGURA 1, verifica-se que houve diferenças significativas entre as misturas de matéria orgânica em propiciar condições adequadas para o enraizamento das estacas, obtendo-se valores máximos de $60 \%$ para as plantas cultivadas em substrato contendo mistura de terra e húmus, e mínimo de $47 \%$ para aquelas cultivadas em substrato contendo mistura de solo e bagana de carnaubeira em proporções iguais. Esses resultados indicam que a adição de húmus a composição do substrato para a produção de mudas por estaquia pode ser possível, embora os resultados alcançados ainda não sejam satisfatórios. Alguns autores recomendam o uso de húmus como componente básico para a formulação de substratos, porque os teores de nutrientes encontrados em sua composição química são bastante elevados (ANDRADE NETO, 1999; OLIVEIRA et al., 2000; SOUZA, 2001).

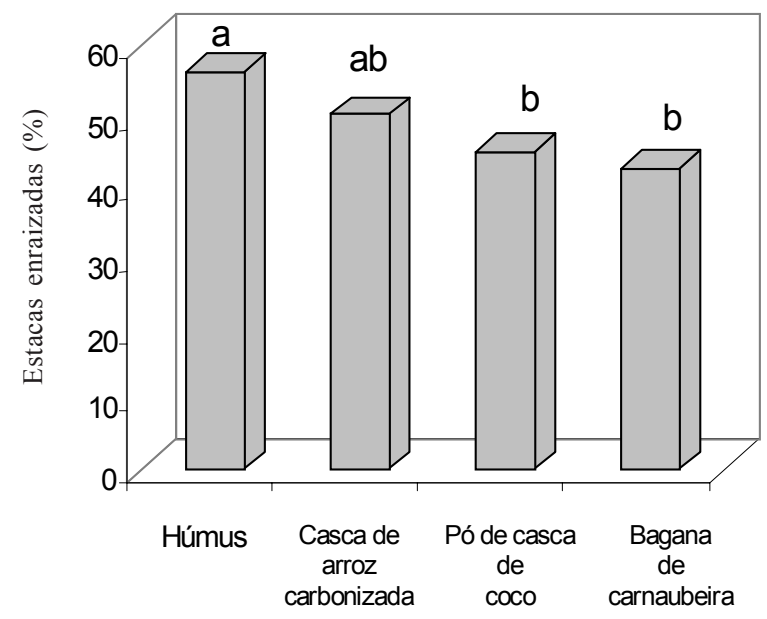

Figura 1 - Percentagem de estacas caulinares enraizadas (\%) de mudas de aceroleira, propagadas por estaquia, em função de fontes de matéria orgânica. Fortaleza-CE, 2002.

Comparando-se os valores obtidos nos substratos contendo mistura de solo e uma das seguintes fontes de matéria orgânica (em partes iguais): casca de arroz carbonizada, pó de casca de coco e bagana de carnaubeira, verifica-se que as mesmas diferiram estatisticamente quanto a propiciar condições adequadas para o enraizamento. A redução de aproximadamente $15 \%$ da emissão de primórdios radiculares observados nas plantas cultivadas em substrato composto por pó de casca de coco seco e bagana de carnaubeira, possivelmente, pode está associada ao elevado teor de tanino e sódio observado no pó de casca de coco seco, e ou a presença de compostos inibidores do processo. Alguns autores mencionam a importância do uso destas fontes de matéria orgânica na formulação de substratos para o enraizamento adventício das estacas caulinares (BEZERRA; BEZERRA, 2000; LIMA; CORREIA, 2001).

Considerando as quatro fontes de matéria orgânica testadas, verificou-se que o número médio de folhas/planta (figura 2), e a massa da matéria seca da parte aérea (figura 3), aumentou, significativamente, com a aplicação do húmus. 


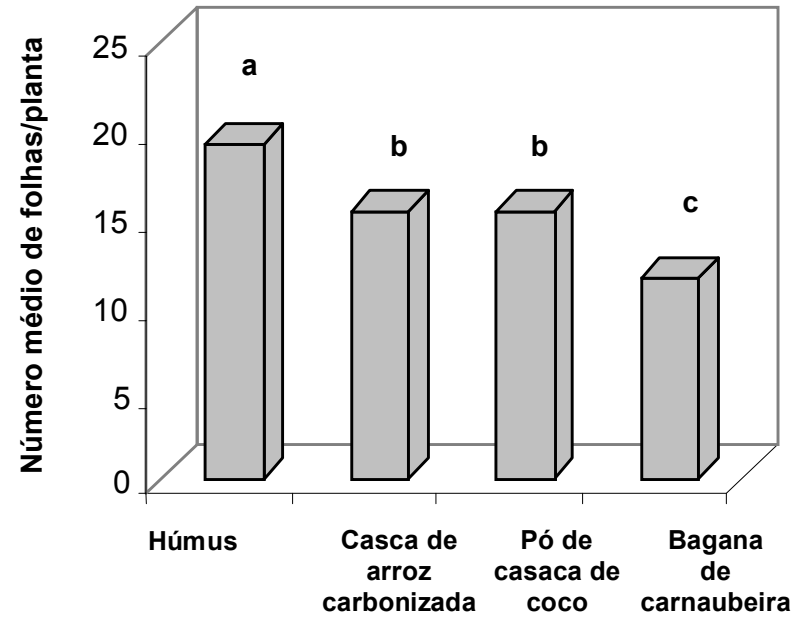

Figura 2 - Número médio de folhas (NF), de mudas de aceroleira, propagadas por estaquia, em função de fontes de matéria orgânica. Fortaleza-CE, 2002.

Observando-se a figura 2, verifica-se que houve efeito significativo, para o número de folhas/planta, em função da composição do substrato. Maior número de folhas foi obtido quando se utilizou mistura de solo e húmus, e o menor valor foi verificado em plantas cultivadas em substrato composto por solo e bagana de carnaubeira. Resultados similares foram observados por Oliveira et al. (2000). Não houve diferenças significativas para o número de folhas/ planta quando foram usados mistura de solo e casca de arroz carbonizada e solo mais pó de casca de coco. A maior média para o número de folhas/planta, quando se usou o substrato contendo húmus, pode ser creditada ao maior teor de nutrientes (LIMA et al., 2001 b) observado na composição química do húmus (tabela 1) que, possivelmente proporcionou maior vigor das plantas. Devido ao maior crescimento de plantas, foi possível obter mudas propagadas assexuadamente em intervalo de tempo inferior ao tempo gasto para produção de mudas usando a propagação sexual, cuja média é de 90 dias (CORRÊA et al., 2000). A diminuição do tempo para atingir o ponto ideal para o transplantio da muda representa custos menores, além de possibilitar a obtenção de maior quantidade de mudas durante o ano.
Tabela 1 - Características químicas de húmus de minhoca (H), casca de arroz carbonizada (CAC), pó de casca de coco seco (PCC) e bagana de carnaubeira (BC) utilizados nos tubetes para a formulação dos substratos. Fortaleza, CE, 2002.

\begin{tabular}{lcccc}
\hline \multirow{2}{*}{ Características } & \multicolumn{4}{c}{ Fontes de matéria orgânica } \\
\cline { 2 - 5 } & $\mathrm{H}$ & $\mathrm{CAC}$ & $\mathrm{PCC}$ & $\mathrm{BC}$ \\
\cline { 2 - 5 } $\mathrm{pH}$ em água $(1: 2,5)$ & 6,5 & 7,0 & 6,2 & 5,1 \\
$\mathrm{Al}\left(\mathrm{cmol}_{\mathrm{c}} \mathrm{dm}^{3}\right)$ & 0,3 & 0,1 & 0,0 & 0,1 \\
$\mathrm{H}+\mathrm{Al}\left(\mathrm{cmol}_{\mathrm{c}} / \mathrm{dm}^{3}\right)$ & 2,8 & 0 & 1,4 & 5,4 \\
$\mathrm{P}\left(\mathrm{mg} / \mathrm{dm}^{3}\right)$ & 386,6 & 104,0 & 20,0 & 20,6 \\
$\mathrm{~K}\left(\mathrm{mg} / \mathrm{dm}^{3}\right)$ & 445 & 490 & 60 & 235 \\
$\mathrm{Ca}\left(\mathrm{mg} / \mathrm{dm}^{3}\right)$ & 12,6 & 0,5 & 0,7 & 4,7 \\
$\mathrm{Mg}\left(\mathrm{mg} / \mathrm{dm}^{3}\right)$ & 7,2 & 0,5 & 1,0 & 2,0 \\
$\mathrm{Na}\left(\mathrm{mg} / \mathrm{dm}^{3}\right)$ & 235 & 37 & 89 & 17 \\
$\mathrm{Fe}\left(\mathrm{mg} / \mathrm{dm}^{3}\right)$ & 21,8 & 11,4 & 16,2 & 23,2 \\
$\mathrm{Zn}\left(\mathrm{mg} / \mathrm{dm}^{3}\right)$ & 11,2 & 2,2 & 4,1 & 1,1 \\
$\mathrm{Mn}\left(\mathrm{mg} / \mathrm{dm}^{3}\right)$ & 12,3 & 8,0 & 2,0 & 23,5 \\
$\mathrm{Cu}\left(\mathrm{mg} / \mathrm{dm}^{3}\right)$ & 2,3 & 0,7 & 0,0 & 0,1 \\
\hline
\end{tabular}

A produção de massa de matéria seca da parte aérea (figura 3) foi maior quando se utilizou mistura de solo e húmus na composição do substrato, e os pesos mais baixos foram obtidos quando se utilizou mistura de solo e pó de casca de coco. A maior produção de matéria seca da parte aérea das plantas cultivadas em substrato contendo húmus também pode ser atribuída à maior fertilidade do substrato, visto que o húmus é um material orgânico rico em $\mathrm{N}$, P, e K (LIMA et al., 2001 b).

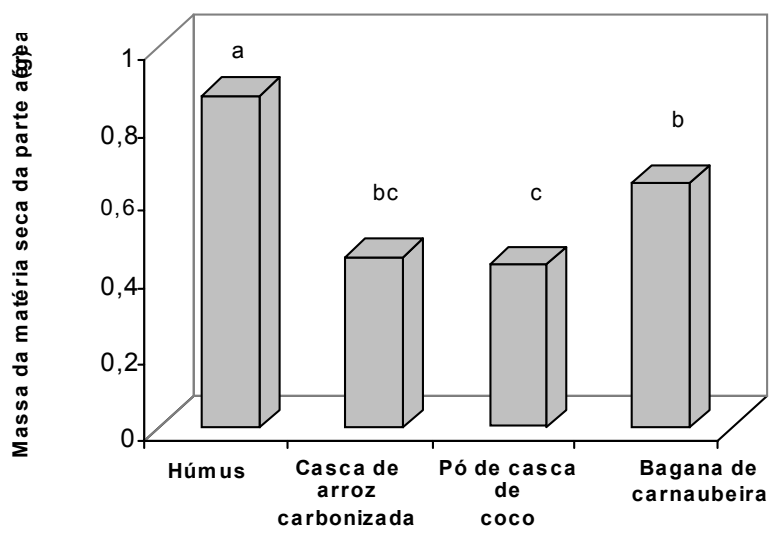

Figura 3 - Massa da matéria seca da parte aérea (g) de mudas de aceroleira, propagadas por estaquia, em função de fontes de matéria. Fortaleza-CE, 2002.

A menor produção de matéria seca da parte aérea foi obtida em plantas cultivadas em substrato contendo 
mistura de solo e pó de casca de coco. Apesar da fibra de casca de coco apresentar baixa densidade, alta porosidade e boa capacidade de retenção de umidade (SOUZA, 2001), características importantes na escolha do material, esta fonte de matéria orgânica apresenta elevados teores de tanino e sódio, que pode explicar, em parte, os resultados obtidos nessa pesquisa.

Observando-se a tabela 2, verifica-se que houve diferenças significativas para a matéria seca do sistema radicular em função do meio de cultivo e do genótipo. Para o genótipo P-91, não houve efeito do substrato sobre o peso de matéria seca de raízes, enquanto para o genótipo P-26 o maior peso ocorreu nas plantas cultivadas em substrato contendo pó de casca de coco seco (PCC) e o menor nas plantas cultivadas em meio contendo bagana de carnaubeira. Embora Stumpf, Grolli e Silva, (1999) e Nicoloso, Fortunato e Fogaça (1999) tenham ressaltado os efeitos benéficos da casca de arroz carbonizada sobre o enraizamento de estacas e desenvolvimento das raízes devido à grande capacidade de aeração, drenagem e possivelmente, à maior umidade volumétrica e porosidade total, o substrato contendo a casca não se destacou nesse experimento.

Tabela 2 - Produção de massa seca pelo sistema radicular de estacas caulinares de progênies de aceroleira (P-91 e P-26) crescidas em quatro fontes de matéria orgânica (húmus, casca de arroz carbonizada (CAC), pó da casca de coco (PCC) e bagana de carnaubeira (BC)). Fortaleza CE, 2002.

\begin{tabular}{ccccc}
\hline \multirow{2}{*}{ PROGÊNIES } & \multicolumn{4}{c}{ FONTES ORGÂNICAS } \\
\cline { 2 - 5 } & $\mathrm{H}$ & $\mathrm{CAC}$ & PCC & $\mathrm{BC}$ \\
\hline P-91 & $0,10 \mathrm{bA}$ & $0,13 \mathrm{aA}$ & $0,13 \mathrm{bA}$ & $0,11 \mathrm{aA}$ \\
P-26 & $0,15 \mathrm{aB}$ & $0,14 \mathrm{aBC}$ & $0,21 \mathrm{aA}$ & $0,11 \mathrm{aC}$ \\
\hline CV (\%) & 9,88 & 5,24 & 13,22 & 0,91 \\
\hline
\end{tabular}

Médias seguidas de mesmas letras minúsculas nas colunas e maiúsculas nas linhas não diferem entre si pelo teste de Tukey a $5 \%$ de probabilidade.

Quando se compara o enraizamento dos dois genótipos usados (tabela 2), verifica-se que houve maior produção de matéria seca de raiz para a progênie 26 na maioria dos meios de cultivo.

A P-26 apresentou maior produção de matéria seca das raízes em relação à P-91, quando foram usados os substratos compostos por pó de casca de coco seco (PCC) e húmus. Na literatura não foram encontrados informações sobre enraizamento adventício, substratos, e genótipos em aceroleira, entretanto para a cajazeira, Oliveira et al. (2000), verificaram que a produção de matéria seca de raiz foi fortemente influenciada pela composição do substrato.

\section{Conclusões}

- O uso de mistura de solo e húmus em partes iguais propiciou condições adequadas para o enraizamento de estacas caulinares de aceroleira, bem como o crescimento da parte aérea e da raiz.

- Substratos compostos por misturas de solo com casca de arroz carbonizada, pó de casca de coco seco e bagana de carnaubeira não exerceram grandes influências sobre a rizogênese e crescimento da muda.

- A capacidade rizogênica da aceroleira depende do genótipo.

\section{Referências}

ANDRADENETO, A.; MENDES, A. N. G.; GUIMARÃES, P. T. G. Avaliação de substratos alternativos e tipos de adubação para a produção de mudas de cafeeiro (Coffea arabica L.) em tubetes. Ciência e Agrotecnologia, Lavras, v. 23, n. 2, p. 270-280, 1999.

BEZERRA, F. C.; BEZERRA, G. S. S. Efeito do substrato na formação de mudas de meloeiro (Cucumis melo). Fortaleza: Embrapa Agroindústria Tropical, 2000. (Pesquisa em Andamento, n. 78).

CORRÊA, M. P. F.; GADELHA, J. W. R.; CORREIA, D.; ROSSETTI, A. G.; RIBEIRO, E. M. Efeito de substratos e da idade do porta-enxerto na formação de mudas de cajueiro anão precoce (Anacardium occidentale L.) em tubetes. Fortaleza: Embrapa Agroindústria Tropical, 2000. (Pesquisa em Andamento, n. 74). 
LIMA, A. C. S.; ALMEIDA, F. A. C.; ALMEIDA, F. C. G. Estudo sobre o enraizamento de estacas de acerola (Malpighia glabra L.). Revista Brasileira de Fruticultura, Cruz das Almas, v. 14, n. 1, p. 7-13, 1992.

LIMA, R. L. S.; CORREIA, D. Evaluation of alternative substrates for production of dwarf cashew grafted seedlings. In: CONGRESO NACIONAL DE LA SOCIEDAD MEXICANA DE CIENCIAS HORTÍCOLAS, 9., 2001, Morelos. Resumos... Morelos, 2001. p. 378.

LIMA, R. L. S.; FERNANDES, V. L. B.; OLIVEIRA, V. H.; HERNANDEZ, F. F. F. Crescimento de mudas de cajueiroanão-precoce 'CCP-76' submetidas a adubação orgânica e mineral. Revista Brasileira de Fruticultura, Jaboticabal, v. 23, n. 2, p. 391-395, 2001 b.

MARCO, C. A.; KERTEN, E.; SILVA, J. G. C. Influência do ethephon e do ácido indolbutírico no enraizamento de estacas de ramos de goiabeira (Psidium guajava L.). Ciência Rural, Santa Maria, v. 28, n. 2, p. 221-224, 1998.

NICOLOSO, F. T.; FORTUNATO, R. P.;FOGAÇA, M. A. F. Influencia da posição da estaca no ramo sobre o enraizamento de Pfaffia glomerata (Spreng.) Pedersen em dois substratos. Ciência Rural, Santa Maria, v. 29, n. 2, p. 277-283, 1999.
OLIVEIRA, D. B.; SOUZA, V. A. B.; VASCONCELOS, L. F.; SOUZA, C. L. C.; CHAGAS OLIVEIRA, F. Avaliação de diferentes substratos, concentrações de AIB e genótipos no enraizamento de estacas lenhosas de cajazeira. In: CONGRESSO BRASILEIRO DE FRUTICULTURA, 16 ., 2000, Fortaleza. Resumos... Fortaleza, 2000. CD-ROOM.

SOUZA, F. X. Materiais para formulação de substratos na produção de mudas e cultivo de plantas envasadas. Fortaleza: Embrapa Agroindústria Tropical, 2001. (Embrapa Agroindústria Tropical. Documentos, 43).

SOUZA, P. V.; MORALES, C. F. G.; KOLLER, O. C.; BARRADAS, C. M. F.; SILVEIRA, D. F. Influência de substratos e fungos micorrízicos no enraizamento de estacas de laranjeira (Citrus sinensis Osb. Cv. Valência). Pesquisa Agropecuária Gaúcha, Porto Alegre, v. 1, n. 1, p. 37-40, 1995.

STUMPF, E. R. T.; GROLLI, P. R.; SILVA, J. A. G. Enraizamento de estacas de Chamaecyparis lawsoniana Parl. em cinco substratos com uso de ácido indolbutírico. Ciência Rural, Santa Maria, v. 29, n. 2, p. 207-211, 1999. 